\title{
Grassland productivity is limited by multiple nutrients
}

Philip A. Fay ${ }^{1 *}$, Suzanne M. Prober ${ }^{2}$, W. Stanley Harpole ${ }^{3-6}$, Johannes M.H. Knops ${ }^{7}$, Jonathan D. Bakker $^{8}$, Elizabeth T. Borer ${ }^{9}$, Eric M. Lind ${ }^{9}$, Andrew S. MacDougall ${ }^{10}$, Eric W. Seabloom ${ }^{9}$, Peter D. Wragg ${ }^{9}$, Peter B. Adler ${ }^{11}$, Dana M. Blumenthal ${ }^{12}$, Yvonne M. Buckley ${ }^{13}$, Chengjin Chu ${ }^{14}$, Elsa E. Cleland ${ }^{15}$, Scott L Collins ${ }^{16}$, Kendi F. Davies ${ }^{17}$, Guozhen Du $^{14}$, Xiaohui Feng ${ }^{18}$, Jennifer Firn $^{19}$, Daniel S Gruner ${ }^{20}$, Nicole Hagenah ${ }^{21}$, Yann Hautier ${ }^{22}$, Robert W. Heckman ${ }^{23}$, Virginia L. $\mathrm{Jin}^{24}$ Kevin P. Kirkmann ${ }^{21}$, Julia Klein ${ }^{25}$, Laura M. Ladwig ${ }^{16}$, Qi Li ${ }^{26}$, Rebecca L. McCulley ${ }^{27}$, Brett A. Melbourne ${ }^{17}$, Charles E. Mitchell ${ }^{23}$, Joslin L Moore ${ }^{28}$, John W. Morgan ${ }^{29}$, Anita C. Risch $^{30}$, Martin Schütz ${ }^{30}$, Carly J Stevens ${ }^{31}$, David A. Wedin ${ }^{32}$, Louie H. Yang ${ }^{33}$

1. USDA-ARS Grassland Soil and Water Research Lab, Temple, TX, 76502 USA

2. CSIRO Land and Water Flagship, Private Bag 5, Wembley, WA 6913, Australia

3. Department of Ecology, Evolution, and Organismal Biology, Iowa State University, Ames, IA, 50011 USA

4. German Centre for Integrative Biodiversity Research (iDiv) Halle-Jena-Leipzig, Deutscher Platz 5e, D-04103 Leipzig, Germany

5. Department of Physiological Diversity, Helmholtz Center for Environmental Research - UFZ, Permoserstr. 15, 04318 Leipzig, Germany

6. Institute of Biology, Martin Luther University Halle-Wittenberg, Am Kirchtor 1, 06108 Halle (Saale), Germany

7. School of Biological Sciences, University of Nebraska, Lincoln, NE, 68588 USA

8. School of Environmental and Forest Sciences, University of Washington, Seattle, WA, 98195 USA

9. Department of Ecology, Evolution, and Behavior, University of MN, St. Paul, MN, 55108 USA

${ }^{10 .}$ Department of Integrative Biology, University of Guelph, Guelph, Ontario, Canada N1G 2W1

11. Department of Wildland Resources and the Ecology Center, Utah State University, Logan, UT, 84322 USA

12. USDA-ARS Rangeland Resources Research Unit, Fort Collins, CO 80526 USA

13. School of Natural Sciences, Zoology, Trinity Centre for Biodiversity Research, Trinity College Dublin, Dublin 2, Ireland

14. Research Station of Alpine Meadow and Wetland Ecosystems, Lanzhou University, Lanzhou, 730000, China.

15. Ecology, Behavior \& Evolution Section, University of California, San Diego, La Jolla, CA, 92093 USA

16. Department of Biology, MSC03-2020, University of New Mexico, Albuquerque, NM, 88003 USA

17. Department of Ecology and Evolutionary Biology, University of Colorado, Boulder, CO, 80309 USA

${ }^{18 .}$ Department of Plant Biology, University of Illinois, Urbana, IL, 61801 USA

19. School of Earth, Environment and Biological Sciences, Queensland University of Technology, Brisbane, Queensland 4001, Australia

${ }^{20 .}$ Department of Entomology, University of Maryland, College Park, MD, 20742 USA

${ }^{21 .}$ School of Life Sciences, University of KwaZulu-Natal, Pietermaritzburg, 3209, South Africa.

22. Ecology and Biodiversity Group, Department of Biology, Utrecht University, Padualaan 8, 3584 CH Utrecht, Netherlands 
23. Department of Biology, University of North Carolina at Chapel Hill, Chapel Hill, NC, 27599 USA

24. USDA-ARS Agroecosystem Management Research Unit, Lincoln, NE, 68538 USA.

25. Department of Forest, Rangeland, and Watershed Stewardship, Colorado State University, Fort Collins, CO, 80523 USA

26. Key Laboratory of Adaptation and Evolution of Plateau Biota, Northwest Institute of Plateau Biology, Chinese Academy of Sciences, Xining, 810008, China

27. Department of Plant and Soil Sciences, University of Kentucky, Lexington, KY, 40546 USA

28. School of Biological Sciences, Monash University, Victoria 3800, Australia.

29. Department of Botany, La Trobe University, Bundoora 3083, Victoria, Australia

30. Swiss Federal Institute for Forest, Snow and Landscape Research, Community Ecology, 8903 Birmensdorf, Switzerland

31. Lancaster Environment Centre, Lancaster University, Lancaster, LA1 4YQ, UK

32. School of Natural Resources, University of Nebraska, Lincoln, NE, 68583 USA

33. Department of Entomology and Nematology, University of California, Davis, CA, 95616 USA.

*To whom correspondence should be addressed (philip.fay@ars.usda.gov)

Terrestrial ecosystem productivity is widely accepted to be nutrient limited ${ }^{1}$. Although nitrogen is deemed a key determinant of aboveground net primary production $^{2,3}$, the prevalence of co-limitation by nitrogen and phosphorus is increasingly recognized $^{4-8}$. However, the extent to which terrestrial productivity is co-limited by nutrients other than nitrogen and phosphorus, such as potassium and micronutrients, has remained unclear. Here, we report results from a standardized factorial nutrient addition experiment, in which we added nitrogen $(N)$, phosphorus $(P)$, and potassium combined with a selection of micronutrients $\left(K_{+\mu}\right)$, alone or in concert, to 42 grasslands spanning five continents, and monitored aboveground net primary production. Nutrient availability limited productivity at 31 of the 42 grassland sites studied. Pairwise combinations of $\mathbf{N}, \mathbf{P}$, and $\mathbf{K}_{+\mu}$ co-limited aboveground net primary production at 24 of the 42 sites, and nitrogen limitation peaked in cool, high latitude sites. Our findings indicate widespread variation in the combination of nutrients that limit aboveground grassland productivity, and highlight the importance of potassium and micronutrients, and an apparent absence of limitation by the nutrients we considered at some sites. This variation in nutrient limitation must be considered when assessing the ecosystem-scale consequences of nutrient enrichment. 
Terrestrial ecosystem productivity is widely accepted to be nutrient limited ${ }^{1}$, and many

2 studies have focused on limitation by a single nutrient, nitrogen $(\mathrm{N})^{2,3}$. In grasslands, and in

3 other systems, the role of additional nutrients is increasingly recognized. A recent meta-analysis

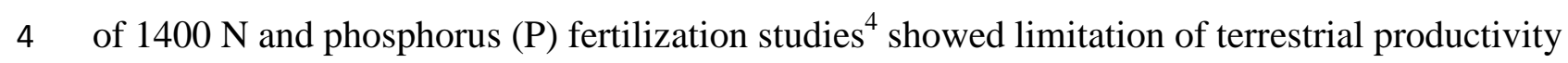

5 by both $\mathrm{N}$ and $\mathrm{P}$. Furthermore, these nutrients often were synergistically co-limiting, where

6 together they limited productivity more than the sum of their individual limitations. This meta-

7 analysis is the most comprehensive assessment of ecosystem nutrient limitation to date.

8 However, the global extent and magnitude of multiple limitation by nutrients other than $\mathrm{N}$ and $\mathrm{P}$

9 remains poorly understood in natural systems $s^{4,5,9}$, including grasslands ${ }^{3,10}$, a critically endangered

10 biome that accounts for approximately one-third of Earth's terrestrial net primary production ${ }^{11}$.

11 More importantly, multiple nutrient limitation has not been experimentally tested in grasslands

12 on a global scale using a standardized experimental approach. The potential for synergistic co-

13 limitation of grasslands by multiple nutrients, or conversely, failing to account for the absence of

14 single or multiple nutrient limitation means we may misestimate the magnitude and extent of

15 nutrient limitation of terrestrial net primary productivity.

16 Humans now produce more reactive $\mathrm{N}$ than is produced from all natural terrestrial

17 sources, primarily as fertilizers, industrial products, and through fossil fuel combustion ${ }^{12,13}$.

18 Anthropogenic increases in atmospheric $\mathrm{N}$ will result in further terrestrial $\mathrm{N}$ deposition, altering

19 ecosystem function ${ }^{12,14-17}$ and potentially increasing limitation by other nutrients, such as P,

20 potassium $(\mathrm{K})$, or trace elements ${ }^{16}$. K occurs in high concentrations in plant tissues ${ }^{18}$ and its

21 uptake is correlated with that of other nutrients ${ }^{19,20}$. Our understanding of limitation by nutrients

22 other than $\mathrm{N}$ in grasslands lags that of agro-ecosystems, where the importance of $\mathrm{P}, \mathrm{K}$, and

23 micronutrients is better understood ${ }^{20}$. 
Here we report the frequency, magnitude, and global extent of nutrient limitation of

25 grassland ANPP by N, P, and K combined with micronutrients $\left(\mathrm{K}_{+\boldsymbol{\mu}}\right)$ at 42 grassland sites in the

26 Nutrient Network (NutNet; Supplementary Material and ${ }^{21}$ ). All sites conducted the same

27 standardized $\mathrm{N}-\mathrm{P}-\mathrm{K}_{+\mu}$ addition experiment, the definitive test for nutrient limitation. This

28 approach overcomes major constraints of previous meta-analyses ${ }^{4}$, differing nutrient addition

29 rates and methodologies and the rarity of factorial nutrient treatments in the underlying studies ${ }^{5}$.

Sites were located on five continents (Supplementary Figure 1) and spanned a 23-fold range in ANPP (Supplementary Figure 2A), over $25^{\circ}$ in absolute latitude (actual latitudes $54^{\circ} \mathrm{N}$

32 to $\left.37^{\circ} \mathrm{S}\right)$, nearly 3,500 $\mathrm{m}$ in elevation, and wide ranges in mean annual precipitation (260 - 1900

$33 \mathrm{~mm})$, mean annual temperature $\left(0.3-22^{\circ} \mathrm{C}\right.$; Supplementary Figure 1$)$, soil texture, and pre-

34 treatment soil N, P, and K pools (Supplementary Table 1). The sites included both native and

35 previously cultivated grassland, and some sites were managed with burning, grazing, or other

36 practices. Thus, we were able to evaluate single and multiple-nutrient limitation of ANPP at

37 global, continental, and site spatial extents, and as influenced by management, climate, and soils.

$\mathrm{N}, \mathrm{P}$, and $\mathrm{K}_{+\boldsymbol{\mu}}$ were factorially applied annually to replicated $5 \mathrm{~m}^{2}$ plots at the beginning

39 of each site's growing season at rates commonly used in grassland fertilization experiments ${ }^{22,23}$.

40 The $\mathrm{K}_{+\mu}$ treatment included a micronutrient mix in the first treatment year only, to avoid

41 micronutrient toxicity. Nutrient limitation of ANPP was quantified by harvesting current year

42 standing crop biomass for 3 to 5 years. and computing the log response ratio (LRR), the natural

43 logarithm of the ratio of treatment plot to control plot ANPP, a metric commonly used in meta-

$44 \quad$ analyses $^{24}$ 
Multiple nutrient limitation of ANPP often occurs in the form of co-limitation ${ }^{5}$. Co-

46 limitation is synergistic when the response to multiple nutrients is greater than the sum of the

47 responses to each nutrient added individually, additive if the multiple-nutrient response equals

48 the sum of the individual nutrient responses, and sub-additive if less than the sum of the single-

49 nutrient responses ${ }^{5}$. Across all sites and years, the combined addition of $\mathrm{N}$ and $\mathrm{P}$ increased

50 ANPP by an average of $40 \%$ over controls ( $\mathrm{LRR}=0.34)$, compared to increases of only $18 \%$

$51 \quad(\mathrm{LRR}=0.16)$ for $\mathrm{N}$ individually and $9 \%$ for $\mathrm{P}$ individually $(\mathrm{LRR}=0.09 ; \mathrm{p}=0.03$, Figure $1 \mathrm{~A}$,

52 Supplementary Figure 3). This provides clear evidence for globally-averaged synergistic co-

53 limitation of ANPP by N and P in these grasslands. Synergistic co-limitation by N and P across

54 sites and years emerged from frequent occurrence of NP co-limitation at the site level. Some

55 form of NP co-limitation averaging $67 \%(\mathrm{LRR}=0.51)$ occurred at $60 \%$ of the sites, including

56 sites on all five continents, with synergistic NP co-limitation at 13 sites and sub-additive co-

57 limitation at 12 sites, (Supplementary Table 3). Globally-averaged synergistic co-limitation of grassland ANPP by $\mathrm{N}$ and $\mathrm{P}$ contradicts the long-held perception that $\mathrm{N}$ is the predominant 59 nutrient limiting grassland productivity ${ }^{3,10}$ and highlights a critical role for $\mathrm{P}$.

There was no globally-averaged single or multiple-nutrient limitation involving $\mathrm{K}_{+\boldsymbol{\mu}}(\mathrm{p}>$

61 0.32, Supplementary Table 2). However, this did not preclude frequent site-level single and

62 multiple-nutrient $\mathrm{K}_{+\boldsymbol{\mu}}$ limitation of grassland ANPP. ANPP was limited at 3 sites by $\mathrm{K}_{+\boldsymbol{\mu}}$ alone

63 and co-limited by $\mathrm{NK}_{+\mu}$ at 18 sites, both averaging 48\% (LRR = 0.39; Figure 1A, Supplementary

64 Table 3). Additionally, ANPP was co-limited by $\mathrm{PK}_{+\boldsymbol{\mu}}$ at 9 sites by an average of 52\% $(\mathrm{LRR}=$

65 0.42), approaching the magnitude of ANPP limitation at sites where N (57\%) or P (54\%)

66 individually limited ANPP (Figure 1A). Site-level $\mathrm{NK}_{+\boldsymbol{\mu}}$ and $\mathrm{PK}_{+\boldsymbol{\mu}}$ co-limitation occurred in

67 synergistic, additive, and sub-additive forms, and in total, single or multiple-nutrient limitation 
involving $\mathrm{K}_{+\mu}$ occurred at 24 sites again occurring on all five continents (Supplementary Table 3). This finding represents the broadest assessment to date of potential $\mathrm{K}_{+\mu}$ limitation of grassland ANPP, and suggests that single- and multiple-nutrient K limitation, potentially augmented by micronutrient addition during year 1 , occurs more frequently than previously recognized $^{20,25}$.

Although single and multiple-nutrient limitation of ANPP was widespread, there were nonetheless 15 sites with no evidence for multiple nutrient limitation, and at 12 of the 15 also no evidence for single-nutrient limitation (Supplementary Table 3). The presence and magnitude of nutrient limitation may depend on site climate, soil development, or fertility ${ }^{26,27}$. For these reasons, greater site-level limitation of ANPP by one nutrient may correlate with greater limitation by one or more additional nutrients. Indeed, site-level individual nutrient limitation of ANPP increased with limitation by other individual nutrients $\left(\mathrm{R}^{2} 0.08-0.15\right.$; Figure 2A,B,D), and ANPP limitation by nutrient pairs increased with that of a third individual nutrient $\left(\mathrm{R}^{2} 0.07\right.$ 0.21; Figure 2C,E,F). These correlations suggest that site-level attributes may predict the magnitude of single and multiple nutrient limitation of ANPP.

Sites differed in various potential qualitative and quantitative predictors of the presence and magnitude of nutrient limitation of ANPP (Supplementary Table 1). We found no evidence that nutrient limitation differed among the qualitative predictors continent, history of management with burning, grazing, and previous cultivation, and predominant soil texture (Supplementary Figure 4, Supplementary Table 4). Quantitative predictors were examined at the 19 longest running sites, where estimates of site mean nutrient limitation should best correspond to site mean climate and soil attributes. $\mathrm{N}$ limitation increased with decreasing site mean annual temperature (MAT; $\mathrm{R}^{2}=0.40, \mathrm{p}=0.002$, Figure $3 \mathrm{~A}$ ) and peaked at temperate latitude sites 
$91\left(\sim 45^{\circ} ; \mathrm{R}^{2}=0.38, \mathrm{p}=0.009\right.$, Figure 3B) with lower MAT $\left(\mathrm{R}^{2}=0.66, \mathrm{p}<0.0001\right.$, Figure 3B

92 inset). Limitation of ANPP by other single or multiple nutrient combinations was not correlated

93 with soil texture fractions, pre-treatment soil nutrient contents, soil $\mathrm{pH}$, or climate variables $(\mathrm{p}>$

$94 \quad 0.05$, data not shown). These findings suggest that $\mathrm{N}$ limitation predominated at cooler

95 temperate latitudes, as others have predicted ${ }^{26}$, and validate the power of these experiments to

96 detect spatial trends in ecosystem nutrient limitation.

The magnitude of single or multiple-nutrient limitation of grassland ANPP may increase through time (Supplementary Figure 2B). To isolate the temporal signal of nutrient addition

99 effects on ANPP, we calculated new ANPP response ratios using the pre-treatment year (i.e., 100 year 0) ANPP for each treatment plot rather than the control plot, to control for plot-to-plot 101 spatial variation in ANPP. For 37 sites with no missing ANPP data in years 1-3, the ANPP 102 response to nutrient addition increased through time in all treatments, ANPP increased each year 103 more in treatments containing $\mathrm{N}(\mathrm{p}<0.005$, Figure 4, Supplementary Table 2$)$ compared to the $104 \mathrm{P}, \mathrm{K}_{+\boldsymbol{\mu}}$, and $\mathrm{PK}_{+\boldsymbol{\mu}}$ treatments. Thus, the larger global-averaged increase in ANPP with $\mathrm{N}$ than $\mathrm{P}$ or $105 \mathrm{~K}_{+\boldsymbol{\mu}}$ (Figure 1A) can be explained partly by both smaller and later manifestation of $\mathrm{P}$ and $\mathrm{K}_{+\boldsymbol{\mu}}$ 106 effects. The full extent of nutrient limitation of grassland ANPP, particularly for nutrients other 107 than $\mathrm{N}$, may require additional years to emerge. Multiple nutrient limitation of ANPP in these grasslands was spatially and temporally varied, often included $\mathrm{K}$ and micronutrients, but sometimes none of the nutrients we considered.

110 Thus, while $\mathrm{N}$ was an important limiting nutrient in many grasslands, $\mathrm{P}$ and $\mathrm{K}_{+\boldsymbol{\mu}}$ were also 111 limiting in many instances, both alone and in combination with each other and with N. These 112 estimates for globally-averaged nutrient limitation in these grasslands are conservative because 
113 nutrient limitation increased in successive treatment years. The magnitude of nutrient limitation

114 may require revision upward if the increases continue in future years.

Multiple nutrient limitation in grasslands, especially synergistic co-limitation, makes the

116 consequences of anthropogenic nutrient inputs in these and other systems more difficult to

117 predict. For example, nutrient co-limitation may actually restrict the impacts of single nutrient

118 inputs such as $\mathrm{N}$ deposition ${ }^{17}$, but ecosystems may respond more rapidly than expected to

119 subsequent inputs of the co-limiting nutrient. Considering only one of the co-limiting nutrients

120 would risk reaching erroneous conclusions about the consequences of future inputs for

121 biodiversity or ecosystem goods/services provision ${ }^{14,15,28,29}$. It is imperative to consider multiple

122 nutrient constraints on primary productivity in grasslands and other ecosystems.

123 Full Methods and any associated references are available in the online version of the paper at

124 www.nature.com/nature.

125 Received |date|; Accepted |date|.

126 Published online |date|.

127

128 Methods

129 Study system

The rationale, goals, and experimental protocols used at grasslands in the Nutrient

131 Network (NutNet) are described in Borer et al. ${ }^{21}$, and are summarized here. This study used

132 aboveground net primary productivity (ANPP) data from a standardized nutrient addition

133 experiment conducted at 42 NutNet sites in eight countries (Australia, Canada, China,

134 Switzerland, Tanzania, United Kingdom, USA, South Africa) on five continents (Australia [N = 
135 4], Africa [ $\mathrm{N}=4$ ], Europe [ $\mathrm{N}=5]$, Asia [ $\mathrm{N}=1]$, North America [ $\mathrm{N}=28]$; Supplementary Figure 136 1, Table 1).

The grassland types included alpine/montane grasslands, shortgrass, mixed, and tallgrass

138 prairies, desert and semi-arid grasslands, old fields and pastures, savanna and shrub-steppe, and

139 annual grasslands. Sites span wide ranges of mean annual precipitation (MAP; 252 - 1898 mm

$140 \mathrm{y}^{-1}$ ), mean annual temperature (MAT; 0.3 - $22.1^{\circ} \mathrm{C}$; Supplementary Figure 1), elevation (50 -

$1413500 \mathrm{~m}$ ), and absolute latitude (over $25^{\circ}$, actual latitudes $54^{\circ} \mathrm{N}$ to $37^{\circ} \mathrm{S}$, Supplementary Table

142 1). Site climate data were derived from the WorldClim database ${ }^{30}$ (version 1.4,). Local

143 investigators classified sites as to management practice (burned, grazed, other management) and

144 native or anthropogenic (restored grassland and agricultural pasture) origin. Sites collected pre-

145 treatment soil nutrient content and texture data.

At each site, $\mathrm{N}, \mathrm{P}$, and $\mathrm{K}$ were added in full factorial combination (8 treatments including

147 control plots) to $5 \times 5$ m plots in a randomized complete blocks design with $\mathrm{N}=3$ for most sites

148 (range 2-6). This experimental scale is well-suited for the relatively short-statured herbaceous

149 vegetation in grasslands. Micronutrients (6\% Ca, 3\% Mg, 12\% S, 0.1\% B, 1\% Cu, 17\% Fe, $150 \quad 2.5 \% \mathrm{Mn}, 0.05 \% \mathrm{Mo}$, and $1 \% \mathrm{Zn}$ ) were added with $\mathrm{K}$ only in year 1 to avoid possible

151 micronutrient toxicity. Nutrient additions began at most sites in $2008(\mathrm{~N}=28)$, and additional

152 sites began in $2009(\mathrm{~N}=9), 2010(\mathrm{~N}=3)$ and $2011(\mathrm{~N}=2)$.

\section{Sampling}

154 Total ANPP $\left(\mathrm{g} \mathrm{m}^{-2} \mathrm{yr}^{-1}\right)$ was estimated annually from clip samples of current year peak 155 aboveground biomass from two $0.1 \mathrm{~m}^{2}$ quadrats per plot. Samples were dried to constant mass at $156 \quad 60^{\circ} \mathrm{C}$. 

174 of continent because of the single Asian site.

\section{Calculation of nutrient effect sizes}

\section{Statistical Analyses} years of nutrient addition.

We tested for nutrient treatment effects on ANPP using linear mixed models in SAS/STAT v 9.2. First, we tested for variation among sites in nutrient main and interactive effects and their variation with treatment year (Equation 1):

$$
\begin{aligned}
\ln (\mathrm{ANPP})_{i j k l} & =\mu+\text { nutrients }_{i}+\text { nutrients }\left(\text { site }_{i j}+{\text { nutrients }(\text { year })_{i k}}\right. \\
& + \text { nutrients(site x year })_{i j k}+e_{i j k l}
\end{aligned}
$$

where nutrients refers to the eight factorial combinations of added $\mathrm{N}, \mathrm{P}$, and K. Nutrient treatments (i) were nested within site $(\mathrm{j})$, within year $(\mathrm{k})$, and within site $\mathrm{x}$ year $(\mathrm{jk})$. Year was not treated as a repeated effect because each site experienced each year differently, and thus both the year effects and the covariance among years were not the same at each site. There were 42 sites with three years of data, 33 sites with four years, and 22 sites with five years. Model (1) was tested using all available treatment years, and with only the first three treatment years to ascertain whether any nutrient $\mathrm{x}$ year interactions were caused by sites added later with fewer

We tested whether ANPP responses to nutrient treatments varied with continent, management, dominant soil texture, and origin by replacing the site term in Eq. 1 with each of the site classification and soils variables, one at a time. Europe and Asia were combined in tests

Effects sizes of the nutrient treatments were calculated and graphed as natural-log response ratios (LRR). LRRs were calculated in two ways; first, by comparing the ANPP of each 
178 treatment plot to the ANPP of the control plot in the same block (2), to isolate treatment effects;

179 and second, by compared treatment plot ANPP to that of its pre-treatment (i.e., year 0) ANPP

180 (3). This isolated the temporal signal of nutrient addition responses.

181

$$
\text { LRR = ln[ANPPtrt/ANPPcontrol] }
$$

We estimated a critical threshold LRR (4) for categorizing the significance of site LRRs. An LRR was considered statistically significant if it exceeded a value corresponding to the critical Z-score (1.65) at $\mathrm{p}=0.05$, computed as:

\section{LRR = $\ln [$ ANPPtrt(year X)/ANPPtrt(year 0)]} Z-score $(1.65)$ at $\mathrm{p}=0.05$, computed as:

$$
\text { Threshold LRR }=1 / 7 *\left(\mathrm{LRR}_{\mathrm{N}}+\mathrm{LRR}_{\mathrm{P}}+\mathrm{LRR}_{\mathrm{K}}+\ldots . . \mathrm{LRR}_{\mathrm{NPK}}\right) / \mathrm{pooled} \mathrm{SD} . \text { (4) }
$$

\section{Correlations of site variables with nutrient effects}

We used linear regression analyses to test whether LRRs for each single nutrient and nutrient pair were predicted by site latitude (absolute value), elevation, mean annual precipitation (MAP), mean temperature annual (MAT), potential evapotranspiration (PET), soil fractions of sand, silt, and clay, pre-treatment soil N, P, and K contents, and soil pH. We presented regressions only where $\mathrm{p}<0.05$, and fit polynomial curves where indicated by evaluation of residuals. 

(Springer, New York, 2011).

Vitousek, P. \& Howarth, R. Nitrogen limitation on land and in the sea: How can it occur? Biogeochemistry 13, 87-115 (1991).

3 LeBauer, D. S. \& Treseder, K. K. Nitrogen limitation of net primary productivity in terrestrial ecosystems is globally distributed. Ecology 89, 371-379 (2008).

4 Elser, J. J. et al. Global analysis of nitrogen and phosphorus limitation of primary producers in freshwater, marine and terrestrial ecosystems. Ecol. Lett. 10, 1135-1142 (2007).

5 Harpole, W. S. et al. Nutrient co-limitation of primary producer communities. Ecol. Lett. 14, 852862 (2011).

6 Bracken, M. E. S. et al. Signatures of nutrient limitation and co-limitation: responses of autotroph internal nutrient concentrations to nitrogen and phosphorus additions. Oikos 124, 113121 (2015).

7 Ågren, G. I. , Wetterstedt, J. Å. \& Billberger, M. F. K. Nutrient limitation on terrestrial plant growth - modeling the interaction between nitrogen and phosphorus. New Phytol. 194, 953-960 (2012).

8 Carnicer, J. et al. Global biodiversity, stoichiometry and ecosystem function responses to humaninduced C-N-P imbalances. Journal of Plant Physiology 172, $82-91$ (2015).

9 Fisher, J. B. , Badgley, G. \& Blyth, E. Global nutrient limitation in terrestrial vegetation. Glob. Biogeochem. Cycles 26, GB3007 (2012).

10 Hooper, D. U. \& Johnson, L. C. Nitrogen limitation in dryland ecosystems: Responses to geographical and temporal variation in precipitation. Biogeochemistry 46, 247-293 (1999).

11 Hoekstra, J. M. , Boucher, T. M. , Ricketts, T. H. \& Roberts, C. Confronting a biome crisis: global disparities of habitat loss and protection. Ecol. Lett. 8, 23-29 (2005).

12 Galloway, J. N. et al. The nitrogen cascade. BioScience 53, 341-356 (2003).

13 Rockstrom, J. et al. A safe operating space for humanity. Nature 461, 472-475 (2009).

14 Stevens, C. J. , Dise, N. B. , Mountford, J. O. \& Gowing, D. J. Impact of nitrogen deposition on the species richness of grasslands. Science 303, 1876-1879 (2004).

15 Fenn, M. E. et al. Ecological effects of nitrogen deposition in the western United States. BioScience 53, 404-420 (2003). 
Mahowald, N. et al. Global distribution of atmospheric phosphorus sources, concentrations and deposition rates, and anthropogenic impacts. Glob. Biogeochem. Cycles 22, GB4026 (2008).

17 Phoenix, G. K. et al. Impacts of atmospheric nitrogen deposition: responses of multiple plant and soil parameters across contrasting ecosystems in long-term field experiments. Glob. Change Biol. 18, 1197-1215 (2012).

$\varnothing$ gaard, A. F. , Krogstad, T. \& Løes, A. K. Potassium uptake by grass from a clay and a silt soil in relation to soil tests. Acta Agr Scand B-S P 51, 97-105 (2001).

19 Veresoglou, D. S. \& Fitter, A. H. Spatial and temporal patterns of growth and nutrient uptake of five co-existing grasses. J. Ecol. 72, 259-272 (1984).

Kayser, M. \& Isselstein, J. Potassium cycling and losses in grassland systems: a review. Grass Forage Sci. 60, 213-224 (2005).

Borer, E. T. et al. Finding generality in ecology: a model for globally distributed experiments. Methods Ecol. Evol. 5, 65-73 (2014).

Guevara, J. C. , Stasi, C. R. , Estevez, O. R. \& Le Houerou, H. N. N and P fertilization on rangeland production in midwest Argentina. J. Range Manage. 53, 410-414 (2000).

Clark, C. M. \& Tilman, D. Recovery of plant diversity following N cessation: effects of recruitment, litter, and elevated N cycling. Ecology 91, 3620-3630 (2010).

24 Hedges, L. V. , Gurevitch, J. \& Curtis, P. S. The meta-analysis of response ratios in experimental ecology. Ecology 80, 1150-1156 (1999).

25

Olff, H. \& Pegtel, D. Characterisation of the type and extent of nutrient limitation in grassland vegetation using a bioassay with intact sods. Plant Soil 163, 217-224 (1994).

26

27

Laliberte, E. et al. Experimental assessment of nutrient limitation along a 2-million-year dune chronosequence in the south-western Australia biodiversity hotspot. J. Ecol. 100, 631-642 (2012).

Wedin, D. A. \& Tilman, G. D. Influence of nitrogen loading and species composition on the carbon balance of grasslands. Science 274, 1720-1723 (1996).

29

Jones, L. et al. A review and application of the evidence for nitrogen impacts on ecosystem services. Ecosystem Services 7, 76-88 (2014).

30 Hijmans, R. J. et al. Very high resolution interpolated climate surfaces for global land areas. Int. J. Climatol. 25, 1965-1978 (2005). 
260 Supplementary Information is linked to the online version of the paper at

261 www.nature.com/nature.

262 Acknowledgements We thank the Minnesota Supercomputer Institute for hosting project data,

263 the University of Minnesota Institute on the Environment for hosting Nutrient Network

264 meetings, and each site investigator for funding their site-level operations. Network coordination

265 and data management were supported by funds from the National Science Foundation Research

266 Coordination Network (NSF-DEB-1042132) to E.T.B. and E.W.S., from the Long Term

267 Ecological Research program (NSF-DEB-1234162) to the Cedar Creek LTER, and from the

268 Institute on the Environment (DG-0001-13). P. Fay acknowledges USDA-NIFA (2010-65615-

269 20632). USDA is an equal opportunity employer and provider.

270 Author Contributions P.A.F. wrote the manuscript, drafted the figures, and led the data

271 analysis; E.M.L., developed the database; S.M.P. and W.S.H. contributed to data analysis;

272 S.M.P., W.S.H., J.M.H.K., J.D.B., E.T.B., A.S.M., E.W.S., and P.D.W. contributed conceptual

273 development and data interpretation. All co-authors contributed data and manuscript editing.

274 This work was generated using data from the Nutrient Network (http://www.nutnet.org)

275 experiment.

276 Author Information The data reported in this paper are available through

277 http://www.nutnet.org. Reprints and permissions information is available at

278 www.nature.com/reprints. The authors declare no competing financial interests. Readers are

279 welcome to comment on the online version of this article at www.nature.com/nature.

280 Correspondence and requests for materials should be addressed to P.A.F.

281 (philip.fay@ars.usda.gov). 
Figure 1

282

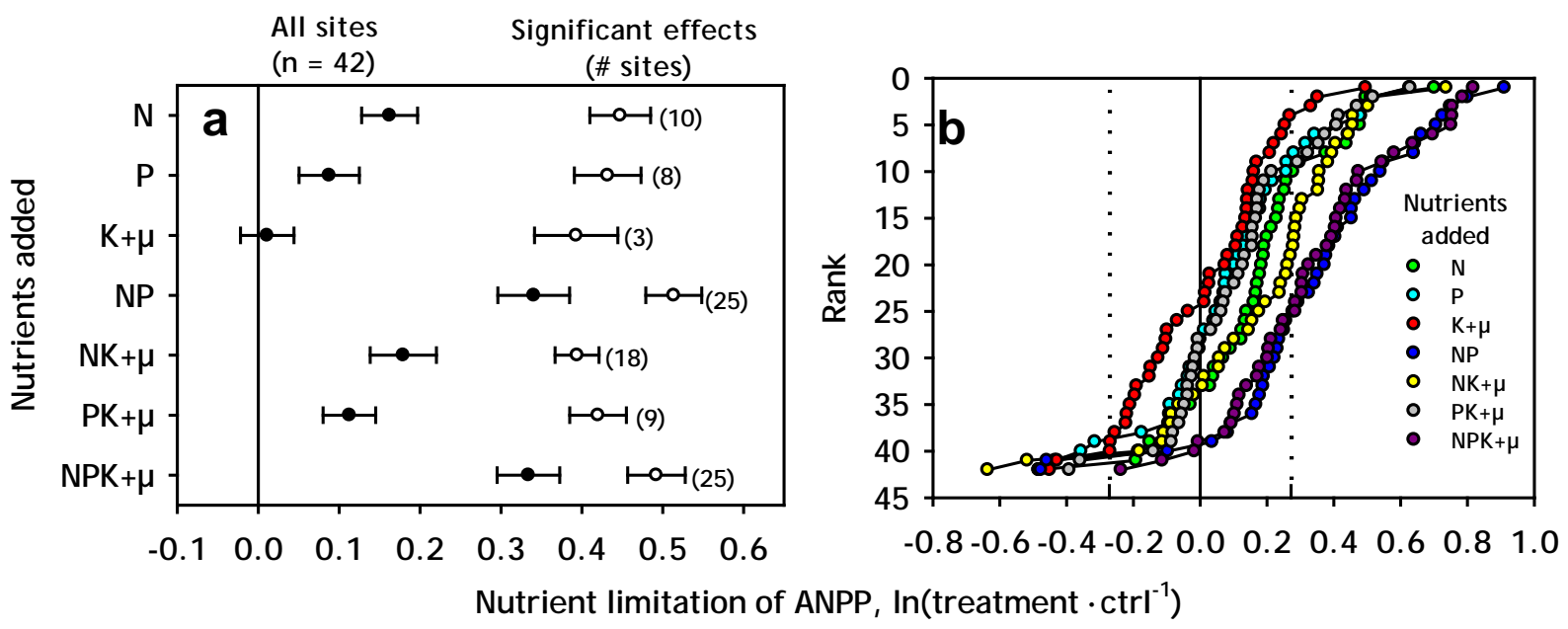

283 Figure 1. Nutrient limitation of aboveground net primary productivity (ANPP; log response

284 ratio, $\ln \left[\right.$ treatment $\left.\cdot \operatorname{control}^{-1}\right]$,) by nitrogen $(\mathrm{N})$, phosphorus $(\mathrm{P})$, and potassium plus year 1

285 micronutrients $\left(K_{+\mu}\right)$. a) Mean \pm SE over all years available at each site. Means for all sites are

286 closed symbols. Means of sites where individual nutrient treatments had significant positive

287 effects (defined in panel b) are open symbols. b) Site nutrient limitation of ANPP ranked by the 288 magnitude of limitation, averaged over all available years. Vertical dashed lines mark the effect 289 sizes approximating a 0.05 significance level for negative and positive nutrient effects on ANPP.

290 Note that sites rank in a different order in each nutrient treatment. 
Figure 2
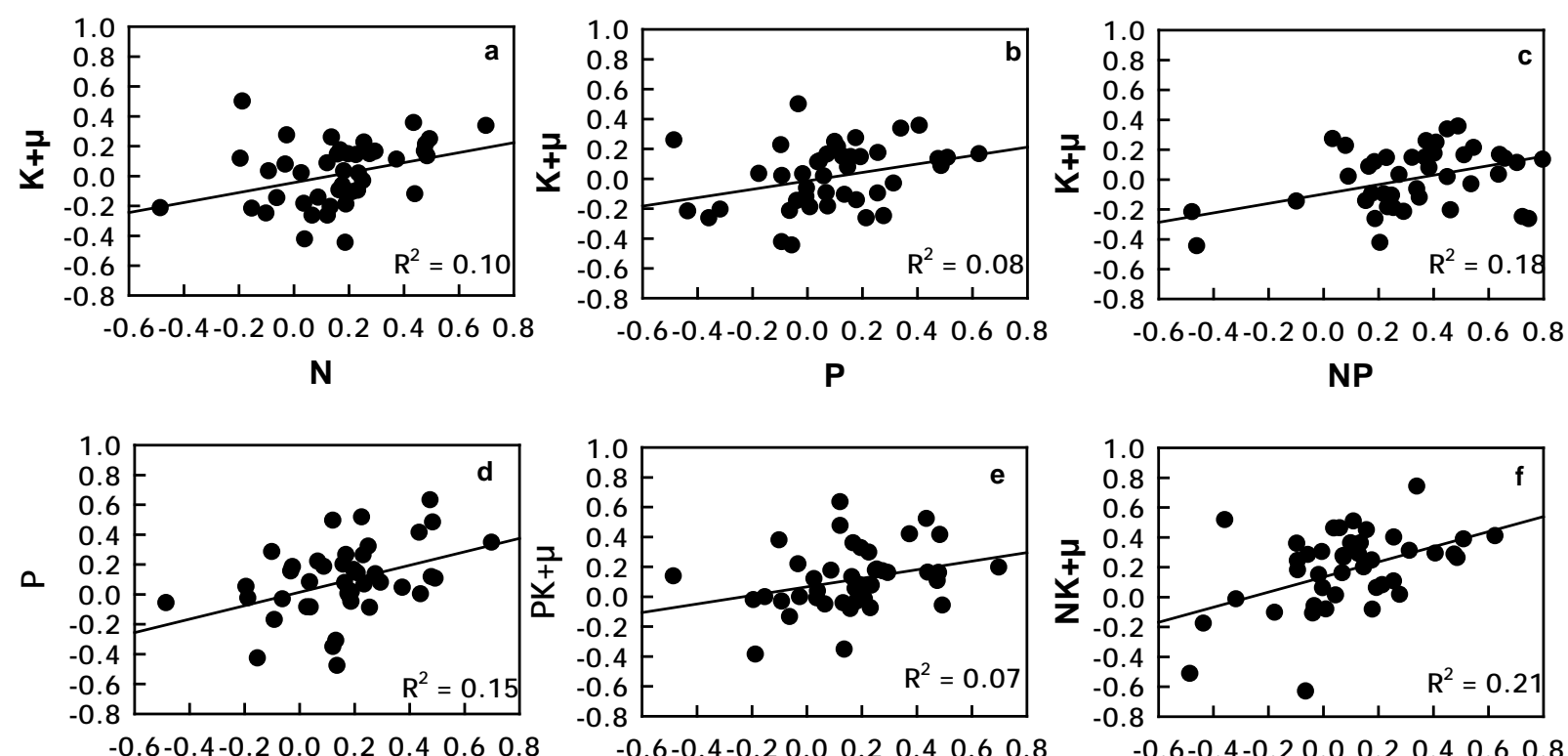

N
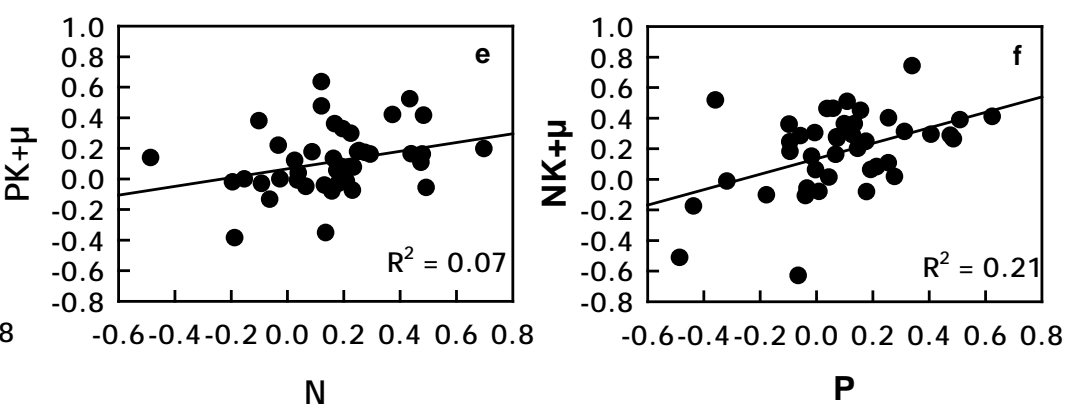

292

Figure 2. Correlations of nutrient limitation of aboveground net primary productivity (ANPP;

$294 \log$ response ratios, $\ln \left[\right.$ treatment $\cdot$ control $\left.^{-1}\right]$ ) among single and paired nutrients. a,b,d)

295 Correlations among single nutrients. c,e,f) Correlations of nutrient pairs with the third nutrient.

296 Coefficients of determination $\left(\mathrm{R}^{2}\right)$ from linear regression $(0.002 \leq P \leq 0.05)$. 
Figure 3

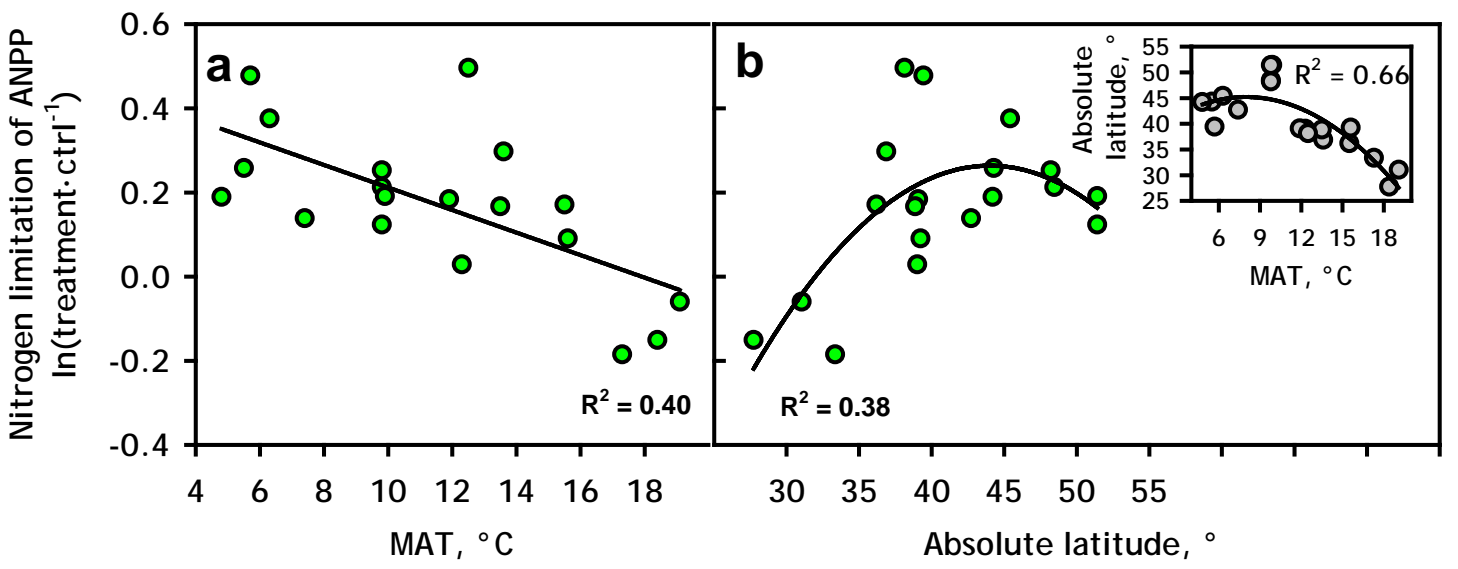

300

301 Figure 3. Predictors of nitrogen (N) limitation of aboveground net primary productivity (ANPP;

$302 \log$ response ratio, $\ln \left[\right.$ treatment $\left.\left.\cdot \operatorname{control}^{-1}\right]\right)$. a) site mean annual temperature (MAT), b) site

303 latitude, in degrees away from the equator, and inset) MAT relationship with site latitude. N

304 limitation values are means of five continuous years of nutrient treatment from 19 sites. 


\section{Figure 4}

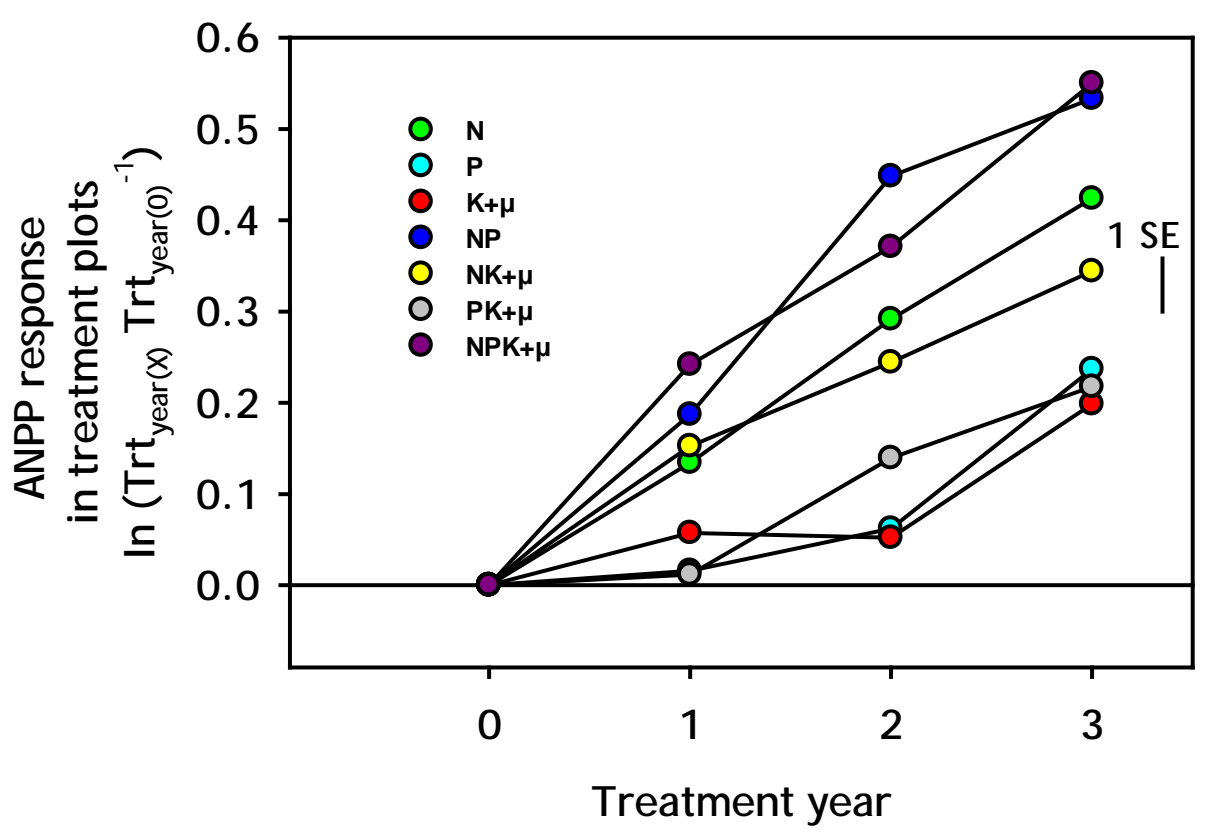

306 Figure 4. Aboveground net primary productivity (ANPP) responses to factorial nitrogen (N),

307 phosphorus $(\mathrm{P})$ and potassium plus year 1 micronutrient $\left(\mathrm{K}_{+\boldsymbol{\mu}}\right)$ treatments by year in 37

308 grasslands with three continuous years of ANPP data. Data represent the mean natural log

309 response ratio of ANPP in the treatment year to ANPP in the pre-treatment year in the same

310 plot, which controls for plot-to-plot variation. 